Medicina Farmacêutica

\section{INDÚSTRIA FARMACÊUTICA: IMPACTO NA EVOLUÇÃO DA PESQUISA CLÍNICA}

No recente $2^{\circ}$ Encontro de Comitês de Ética do Estado de São Paulo, ocorrido em São Paulo, por iniciativa da Sociedade Brasileira de Medicina Farmacêutica -SBMF; o Sr. Gabriel Tannus, presidente da Interfarma - Associação da Indústria Farmacêutica de Pesquisa, apresentou interessantes dados de cerca de 30 indústrias presentes no país, concernentes à sua participação na pesquisa clínica.

$\mathrm{O}$ aspecto que primeiramente chama à atenção e que reflete o crescente investimento das indústrias de pesquisa nesse setor, é que, de I980 a 200I, o percentual sobre vendas destinado à pesquisa e desenvolvimento aumentou de $12 \%$ para $21 \%$, respectivamente. Nesse quesito em particular, a indústria farmacêutica ocupa a liderança, em relação aos demais segmentos econômicos locais, como se pode observar: Farmacêutica: 21\%; Telecomunicações: 5\%; Média das indústrias nos Estados Unidos: 4\%; Automotiva: 4\%; Eletrônica: 6\%.

Esse alto investimento - imprescindível à manutenção das atividades de pesquisa e desenvolvimento - é, entre outros, um dos responsáveis pela crescente ocorrência de fusões neste setor. Sabe-se, por exemplo, que para se chegar a um único produto, o processo - que dura cerca de 10 a 12 anos - deve começar por analisar entre cinco a dez mil compostos químicos. Para isso, o centro de estudos Tufts Center for the Study of Drug Development estimou que em 2003 foram investidos cerca de US\$897 milhões.

$O$ resultado de todo esse investimento - o novo medicamento - deve, então, após o seu "nascimento", batalhar por seu "posto" de "inovação", de forma cada vez mais ágil e competitiva, em nome da manutenção de sua viabilidade no mercado. Um medicamento tem 20 anos de exclusividade, a partir do início da patente, no tocante aos genéricos, mas em relação ao mercado, ele tem um prazo muito menor. Tome-se como exemplo o medicamento Inderal, que, lançado em 1966, existiu por 12 anos sem concorrência, enquanto que o Prozac (1987), quatro anos depois de lançado, já teve de se deparar com seu primeiro concorrente na categoria, o Zoloft (|99|). O Mevacor, lançado em 1997, reinou exclusivo, também por quatro anos, até que o Pravacol surgiu em 1991. Já o Invirase, mais jovem e lançado em dezembro de 1995, teve apenas três meses de exclusividade, tendo de se deparar com o Norvir, em março de 1996.

A despeito dessas dificuldades com que as indústrias devem se deparar hoje, é que delas provêm a grande maioria dos produtos disponibilizados comercialmente, ficando cerca de apenas $1 \%$ deles por conta da produção das universidades.

O resultado do trabalho das indústrias tem contribuído significativamente, ao longo dos anos, para 0 aumento da expectativa de vida e redução dos índices de mortalidade de diversas doenças. Tome-se como exemplo a expectativa de vida no Brasil, que, em 1950, era de 43 anos e em 2000, passa a 69 anos.
O mesmo se verifica nos Estados Unidos, quando em 1900, a expectativa de 47 anos passa a 78 anos, no ano de 2000. Concomitantemente, reduzem-se as taxas de mortalidade de algumas doenças como febre reumática em $83 \%$, úlcera péptica em $72 \%$, isquemia miocárdica em $62 \%$, enfisema pulmonar: $57 \%$, hipertensão arterial em $21 \%$. Cabe ainda lembrar que a redução na mortalidade por AIDS, por conta das novas condutas, particularmente do uso do coquetel, tendo hoje, os aidéticos, sobrevida e qualidade de vida supe riores graças aos medicamentos. A vertiginosa dimi nuição da transmissão materno-fetal também devida aos avanços da indústria farmacêutica, entre outras ações, deve ser mencionada.

Havia, em 2000, nos Estados Unidos, 46 mil médicos envolvidos em pesquisa clínica. Na mesma época três mil participavam de protocolos na América Latina. Essa diferença, devido ao passado do trabalho de pesquisa no Brasil, que não the conferiu credibilidade internacional, vem caindo progressivamente. Sempre dispusemos de grandes talentos, mentes brilhantes e conhecimento técnico; faltava-nos, todavia, instrumentos, incentivos e financiamento. Um grande passo foi dado em 1996, com a criação dos Conselhos de Ética em Pesquisas (CEP), conquista de espaço no mundo científico e de respeito por nossos pesquisadores e seus trabalhos. Estima-se que para 2010 essa desproporção acima se altere para 80 mil nos EUA e 30 mil na América Latina.

\section{Comentário}

Em 2003, cerca de 30 indústrias, em cujos dados baseou-se a apresentação do Sr. Gabriel Tannus, investiram $R \$ 153,1$ milhões contra $R \$ 21,9$ milhões, em 1995. Por questões burocráticas e, em algumas instâncias, por falhas de comunicação por parte dos responsáveis, cerca de US\$ 65 milhões deixaram de ser aplicados em pesquisas clínicas no Brasil. O tempo para aprovação das pesquisas clínicas ainda é muito longo e o planejamento das pesquisas obedece a cronogramas rígidos, que não permitem atrasos em sua implementação. Para se ter uma idéia, o tempo para aprovação das pesquisas clínicas na Suécia é de cerca de oito semanas, caindo no Canadá e França para seis semanas, contra cinco na Suécia e no Brasil, vinte e três semanas. Sem respeito a esses prazos, o País perde poder competitivo, principalmente perante outras nações da América Latina, como México e Argentina. É preciso que se encontrem caminhos junto aos órgãos oficiais (CEPs, a CONEP e ANVISA), que possibilitem redução desse prazo de aprovação. A adequada integração indústria-universidadegoverno pode e deve contribuir decisivamente para tornar o Brasil mais competitivo. As indústrias vêm trabaIhando no sentido se tentar acelerar esse tempo, sem prejuízo da ética e da legislação: a simplificação buro crática e a eliminação de impostos sobre produtos e aparelhos destinados exclusivamente a pesquisas podem proporcionar ao País um melhor lugar ao sol dentro do cenário mundial da pesquisa. Assim, todos nós brasileiros nos beneficiamos também.

Paulo Aligieri Gabriel Tannus ELEONORA Lins

\section{Referência}

I.Tannus G. A Interfarma e o progresso da pesquisa clínica no Brasil. In: $2^{\circ}$ Encontro de Comitês de Ética do Estado de São Paulo. São Paulo: Sociedade Brasileira de Medicina Farmacêutica; Julho 2004

\section{Medicina Farmacêtica}

\section{REGISTRO DE ENSAIOS CLÍNICOS: DECLARAÇÃO DO COMITÊ INTERNACIONAL DE EDITORES DE REVISTAS MÉDICAS}

Editorial publicado em setembro último em todos os jornais membros do International Committee of Medical Journal Editors (ICMJE) evoca a necessidade do registro de todos os ensaios clínicos - independentemente de seus resultados positivos, negativos ou inconclusivos - em banco de dados público, de fácil acesso eletrônico e gratuito. O objetivo final dessa medida é a transparência total na condução e relato dos resultados de estudos de pesquisa clínica em humanos que avaliam ou comparam intervenções terapêuticas. Consideram que os pacientes que participam dos ensaios devem saber que a sua contribuição para a melhora da saúde humana estará disponível, quando da tomada de decisões em saúde e que o conhecimento que se tornou possível graças à sua colaboração estará acessível a todos.

Alertam os editores que se vê mais entusiasmo - tanto por parte dos investigadores como por parte dos editores dos jornais - na publicação de ensaios que demonstrem a superioridade de um novo tratamento ou a sua não-inferioridade. Não há grande interesse na leitura de estudos que mostrem resultados negativos e, menos ainda, em estudos que não sejam claramente negativos ou positivos, posto que não alteram a prática corrente. Estudos que envolvam grande interesse financeiro são especialmente propensos a permanecerem desconhecidos, independentemente de seu interesse científico. Por fim, que resultados de pequisa de estudos selecionados por patrocinadores ou investigadores não deveriam poder influenciar o pensamento de pacientes, clínicos, outros pesquisadores e especialistas que redigem diretrizes ou detêm poder de decisão sobre políticas de coberturas de saúde.

Hoje o registros dos estudos e suas características é totalmente voluntário, contém apenas uma pequena proporção dos ensaios e o acesso público a seus dados é variável. Sendo todos os estudos depositados em um mesmo arquivo público, desde sua concepção, todos os pesquisadores podem explorar a ampla variação de evidências clínicas.

Anunciam que II periódicos membros do ICMJE adotarão políticas de registro de ensaios para que se possa atingir esse objetivo: 